\title{
Heavy Metals in Agricultural Soils of the Lihe River Watershed, East China: Spatial Distribution, Ecological Risk, and Pollution Source
}

\author{
Lian Chen ${ }^{1,2}$, Genmei Wang ${ }^{3, *}$, Shaohua Wu ${ }^{4}$, Zhen Xia ${ }^{1, *}$, Zhenang Cui ${ }^{1}$, Chunhui Wang ${ }^{5}$ \\ and Shenglu Zhou ${ }^{2}$ \\ 1 Guangzhou Marine Geological Survey, 477 Huanshi East Road, Guangzhou 510075, China; \\ dg1527004@smail.nju.edu.cn (L.C.); cuizhenang@163.com (Z.C.) \\ 2 School of Geography and Ocean Science, Nanjing University, 163 Xianlin Road, Nanjing 210023, China; \\ zhousl@nju.edu.cn \\ 3 College of Forestry, Nanjing Forestry University, 159 Longpan Road, Nanjing 210037, China \\ 4 Institute of Land and Urban-Rural Development, Zhejiang University of Finance \& Economics, \\ Hangzhou 310018, China; shaohua@zufe.edu.cn \\ 5 College of Materials and Environmental Engineering, Hangzhou Dianzi University, Hangzhou 310018, \\ China; wch@nju.edu.cn \\ * Correspondence: wanggenmei@njfu.edu.cn (G.W.); xia-zhen@163.com (Z.X.); \\ Tel.: +86-025-85428629 (G.W.); +86-020-82251561 (Z.X.)
}

Received: 29 March 2019; Accepted: 4 June 2019; Published: 13 June 2019

\begin{abstract}
Concentrations of cadmium, chromium, copper, nickel, lead, and zinc in agricultural soils at 32 sites in the Lihe River Watershed of the Taihu region, East China, and their potential ecological risks and possible sources were investigated. Enrichment factor analysis demonstrated enrichment in the order $\mathrm{Cd}>\mathrm{Pb}>\mathrm{Zn}>\mathrm{Cu}>\mathrm{Ni}>\mathrm{Cr}$. The potential ecological risk index and risk assessment code analyses indicated that, of the metals studied, Cd posed the most significant ecological risk in the study area. Statistical analyses, GIS mapping, and enrichment factor analysis suggested that $\mathrm{Cd}, \mathrm{Pb}$, $\mathrm{Cu}$, and $\mathrm{Zn}$ were derived mainly from anthropogenic sources, including agricultural, industrial, and vehicular emissions, while $\mathrm{Cr}$ and $\mathrm{Ni}$ were mainly from natural sources. Positive matrix factorization revealed that $\mathrm{Cd}, \mathrm{Cr}, \mathrm{Cu}, \mathrm{Ni}, \mathrm{Pb}$, and $\mathrm{Zn}$ were sourced from industrial and vehicular emissions $(73.7 \%, 21.3 \%, 71.4 \%, 20.3 \%, 75.0 \%$, and $62.2 \%$, respectively), the agricultural sector $(26.3 \%, 36.3 \%$, $6.8 \%, 38.9 \%, 15.7 \%$, and $6.9 \%$, respectively), and parent materials $(0 \%, 42.4 \%, 21.8 \%, 40.8 \%, 9.2 \%$, and $30.9 \%$, respectively). It was recommended that strategies be implemented to reduce industrial point-source pollution.
\end{abstract}

Keywords: source apportionment; GIS mapping; enrichment factor; PMF; industrial and agricultural activity; parent material

\section{Introduction}

Rapid urbanization and industrialization over recent decades have resulted in heavy metal contamination of agricultural soils, and heavy metal pollution of agricultural soil has become a worldwide environmental concern [1-5]. Heavy metal accumulation in soils can significantly affect human health through their environmental persistence, bioaccumulation, and transfer through food chains; consequently, control of pollution sources is required to minimize their impact [6]. The effective assessment of ecological risks and source apportionment is a crucial step in this regard.

Numerous analytical techniques have been applied in assessing ecological risks posed by heavy metals in agricultural soils, based on their concentration, distribution, and speciation [7-9]. 
Wang et al. [9] used the potential ecological risk index (PERI) to quantify degree of metal pollution and assess the ecological risk of heavy metals in soils. Although the PERI considers the toxicity and total concentrations of heavy metals, a degree of subjective assessment is involved and chemical speciation is ignored $[8,10,11]$, even though toxicity and mobility are strongly dependent on the latter $[12,13]$. The risk assessment code (RAC) was introduced because of the advantage of comprehensive analysis of heavy metals and other components in soil, providing a better indication of relationships between bioavailability and mobility, as well as environmental risk $[8,14]$. Until now, there has been no systematic or integrated research focusing on ecological risk assessment of heavy metal contamination in the Lihe River Watershed in East China. In addition, the relevance of acid-soluble fractions of heavy metals, and source apportionment in this region, have not yet been investigated.

It is generally considered that heavy metals originate from two primary sources: natural (e.g., weathering of parental material) and anthropogenic (e.g., metalliferous industries, mining, vehicle exhausts, and agronomic practices) $[1,2,15,16]$. Existing methods of heavy metal source apportionment include descriptive statistical methods (coefficient of variation $(\mathrm{CV})$ and correlation analysis), geographic information system (GIS) mapping, enrichment factor (EF) analysis, and positive matrix factorization (PMF). The $\mathrm{CV}$, correlation, and $\mathrm{EF}$ analysis approaches determine roughly which heavy metals may be homologous, and which may be from anthropogenic or natural sources [17-19]. GIS mapping can estimate and quantify the spatial distributions of heavy metals [2,20-23], and provide additional information to distinguish point from non-point sources and identify potential pollutant sources $[2,24,25]$. However, these methods provide approximations only, and cannot definitively quantify the relative source contributions. PMF is therefore more widely used, because it estimates source component spectra based on a weighted-least-squares method and decomposes sample data into two matrices, namely the 'factor-contribution' and 'factor-component' matrices or spectra [26]. In previous studies, CV and correlation analysis, GIS mapping, EF analysis, and PMF have commonly been used alone, whereas the present study represents an attempt to integrate and apply all methods to a single site, thereby enabling cross-verification and the generation of more accurate and reliable results.

Unlike other studies, a research story in our study from pollution distribution to pollution assessment to sources apportionment was clearly and integrally described at sites in the Lihe River Watershed of the Taihu region, East China. Additionally, from the specific implementation details, a novel systematic risk assessment and a combined method of source apportionment for heavy metals were conducted. The aims were to (1) investigate the concentrations and spatial distribution patterns of $\mathrm{Cd}, \mathrm{Cr}, \mathrm{Cu}, \mathrm{Ni}, \mathrm{Pb}$, and $\mathrm{Zn}$ in agricultural soils of the Lihe River Watershed; (2) assess the ecological risks posed by these metals based on combined PERI and RAC methods; and (3) identify the natural and anthropogenic sources of the metals and also calculate their contribution rate by combining CV and correlations analysis, GIS mapping, EF analysis, and PMF. The results provide insights into the management of heavy metal pollution in the Lihe River Watershed, and this study serves as a reference for other regions both in China and worldwide.

\section{Materials and Methods}

\subsection{Study Area}

The study area, in the Lihe River Watershed, is located to the west of Taihu Lake, Yixing City, Jiangsu Province, China. It includes two towns, Hufu and Dingshu, and is bounded by the coordinates $31^{\circ} 09^{\prime} 00^{\prime \prime}-31^{\circ} 20^{\prime} 31^{\prime \prime} \mathrm{N}$ and $119^{\circ} 42^{\prime} 00^{\prime \prime}-119^{\circ} 56^{\prime} 20^{\prime \prime} \mathrm{E}$. Lihe River watershed has a surface area of $\sim 260 \mathrm{~km}^{2}$, and agricultural land makes up $41 \%$ of the area [27]. There is a high density of industrial activity in the area, including a ceramics factory, a refractory materials plant, and a chemical plant, among others.

This study area was chosen because a previous study involving potential ecological risk assessment of heavy metal pollution in estuaries of the 24 main rivers flowing in and out Taihu Lake revealed that the Lihe River estuary was the most seriously contaminated [14]. However, there has been scant research into risk assessment and the source apportionment of heavy metals in this high-risk area. 


\subsection{Sample Collection and Preparation}

Soils in crop fields were sampled at $0-10 \mathrm{~cm}$ depth from 32 randomly selected sites throughout the study area in May 2016 (Figure 1). The crop grown in the soil was wheat. Each sample of $0.5-1.0 \mathrm{~kg}$ was divided into 5-9 subsamples. The samples were air-dried at room temperature, ground, and passed through a $2 \mathrm{~mm}$ nylon sieve to remove stones and plant roots. The fine soil powders were then stored in polythene zip bags [28].

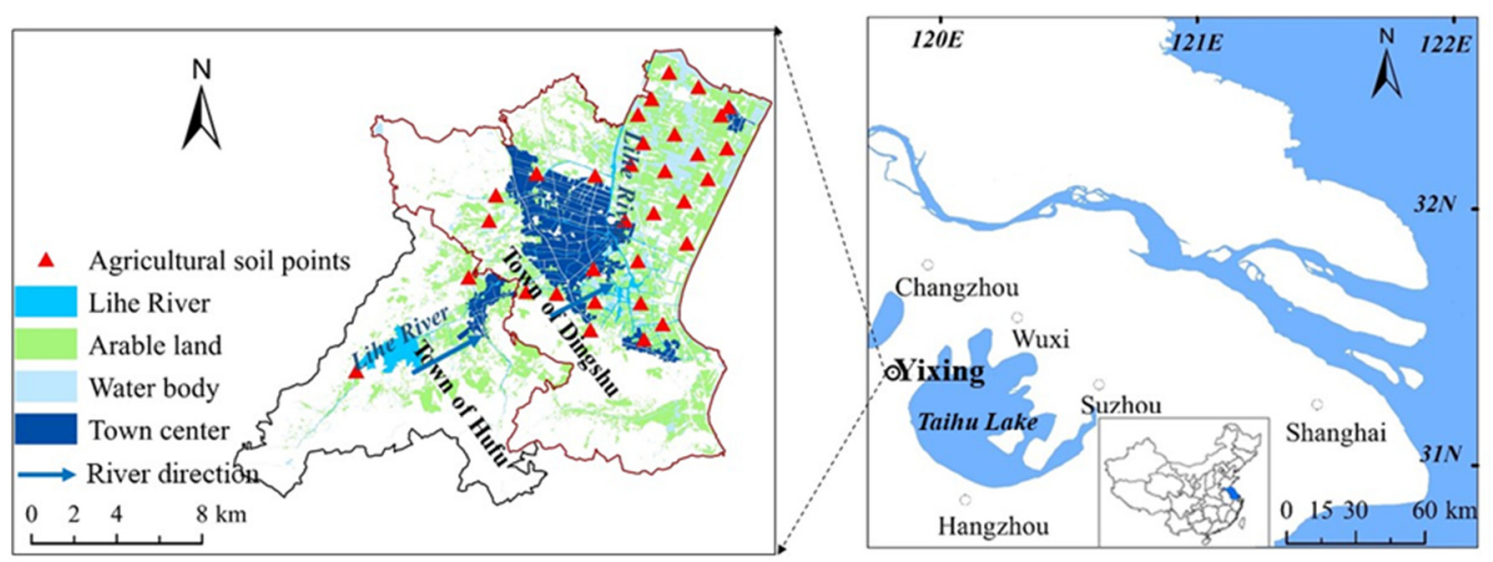

Figure 1. Location of the study area and distribution of sampling points.

\subsection{Chemical Analysis}

\subsubsection{Soil Properties}

Measurements of the particle size distribution were conducted using a MALVERN 2000 Laser particle size analyzer. The samples first received ultrasonic treatment in a $20 \%\left(\mathrm{NaPO}_{3}\right)_{6}$ solution, and then 3 cycles were measured with the analyzer to obtain $1 / 4$ interval distribution of granularity data $[3,4,29,30] ; \mathrm{pH}$ values of the soils were determined using a $10 \mathrm{~g}$ sample mixed with $25 \mathrm{~mL}$ of distilled water, which was stirred and left at room temperature $\left(25^{\circ} \mathrm{C}\right)$ for $0.5 \mathrm{~h}$ and then determined by a $\mathrm{pH}$ electrode [31]; loss-on-ignition method was used to analyze the soil organic matter (OM). Soil samples with constant weight were burned at $550{ }^{\circ} \mathrm{C}$ in a muffle in this process [32]; cation exchange capacity (CEC) was measured by the extraction method, using ammonium acetate $\left(\mathrm{NH}_{4} \mathrm{OAc}\right)$ and potassium chloride $(\mathrm{KCl})$ [32]. A conductivity meter (Mettler Toledo) was used to measure the soil electrical conductivity (EC). Firstly, a suspension of 1:5 soil-water was configured and centrifuged for $30 \mathrm{~min}$, and the clear supernatant extract was then used to test conductivity [33].

\subsubsection{Total Heavy Metal Concentrations}

Total heavy metal concentrations were determined by $\mathrm{HCl} / \mathrm{HNO}_{3} / \mathrm{HF} / \mathrm{HClO}_{4}$ extraction. Approximately $100 \mathrm{mg}$ of each sample was digested with $3 \mathrm{~mL} \mathrm{37 \%} \mathrm{HCl}, 1 \mathrm{~mL} 65 \% \mathrm{HNO}_{3}, 6 \mathrm{~mL}$ $65 \% \mathrm{HF}$, and $0.5 \mathrm{~mL} 65 \% \mathrm{HClO}_{4}$, using a two-stage digestion program involving heating for $10 \mathrm{~min}$ to $200{ }^{\circ} \mathrm{C}$, and $15 \mathrm{~min}$ at $200{ }^{\circ} \mathrm{C}$ [34]. After cooling, the digestion solutions were evaporated to near dryness and the residue was dissolved in $1.0 \mathrm{~mL} 65 \% \mathrm{HNO}_{3}$, after which deionized water $(20 \mathrm{~mL})$ was added. These solutions were stored in $25 \mathrm{~mL}$ high-density polyethylene vials at $4{ }^{\circ} \mathrm{C}$ until instrumental analysis [34]. Concentrations of $\mathrm{Cd}, \mathrm{Zn}, \mathrm{Pb}, \mathrm{Cu}, \mathrm{Cr}$, and $\mathrm{Ni}$ in each solution were determined by inductively coupled plasma-mass spectrometry (ICP-MS; Perkin Elmer SCIEX, Elan 9000, Perkin Elmer Inc., America). Instrumental conditions are listed in Table S1 of the Supplementary Materials.

\subsubsection{Acid-Soluble Heavy Metal Fractions}

Acid-soluble heavy metal fractions were determined by $0.1 \mathrm{~mol} \mathrm{~L}^{-1} \mathrm{HCl}$ extraction [34]. Approximately $5 \mathrm{~g}$ of soil was placed in a pre-weighted $15 \mathrm{~mL}$ plastic centrifuge tube and the 
exact mass was recorded. $\mathrm{HCl}\left(5 \mathrm{~mL}, 0.1 \mathrm{~mol} \mathrm{~L}^{-1}\right)$ was added and the tube was shaken for $4 \mathrm{~h}$ on an oscillating table. After shaking, the mixture was allowed to stand for $24 \mathrm{~h}$ before concentrations of $\mathrm{Cd}$, $\mathrm{Zn}, \mathrm{Pb}, \mathrm{Cu}, \mathrm{Cr}$, and $\mathrm{Ni}$ were determined by ICP-MS.

\subsubsection{Quality Assurance and Control}

Quality assurance (QA) and quality control (QC) involved analysis of replicate samples, method blanks, and standard reference materials, with duplicate analyses. Three replicate samples were analyzed, with relative standard deviations (RSD) for metal concentrations being no greater than $5 \%$ in all cases. All analyses were duplicated, and results are expressed as mean concentrations. Standard reference material GBW07405 (National Research Center for Standards in China) was used to verify analytical accuracy. All reagents were analytical grade or better. The lab glassware (bottles, tubes, etc.) was pre-cleaned by soaking in $10 \% \mathrm{HNO}_{3}$ for at least two days, followed by soaking in and rinsing with de-ionized water prior to use.

\subsection{Assessment of Soil Contamination}

\subsubsection{Potential Ecological Risk Index}

The PERI, introduced by Hakanson (1980), is used to assess the potential ecological risk of heavy metals in soil. This method not only assesses the pollution status of the soil, but also combines ecological and environment effects with toxicology, providing a better indication of potential risks denoted by index values. The potential ecological risk factor of a given metal $\left(E_{i}\right)$ is defined as:

$$
E_{i}=T_{i} \times\left(C_{i} / C_{0}\right)
$$

Equation (2) was used to calculate the total risk index (RI) of a sampling site, as follows:

$$
R I=\sum_{i=1}^{n} E_{i}
$$

where $C_{i}$ is the concentration of metal $i$ in soil, $C_{0}$ is the background concentration, $T_{i}$ is the biological toxicity factor of an individual element ( $T_{i}$ values are as follows: $\mathrm{Cu}=\mathrm{Pb}=\mathrm{Ni}=5, \mathrm{Zn}=1, \mathrm{Cr}=2$, and $C d=30[8,35,36], E_{i}$ is the potential ecological risk factor of metal $i$, and $R I$ is the total potential ecological risk index of metals $i-n$. The PERI of heavy metals was categorized according to five levels, as shown in Table 1.

Table 1. Classification of potential ecological risk index (PERI).

\begin{tabular}{cccccc}
\hline \multirow{2}{*}{ Assessment Criterion } & \multicolumn{5}{c}{ PERI } \\
\cline { 2 - 6 } & Low & Moderate & Considerable & High & Very High \\
\hline$E_{i}$ & $<40$ & $40-80$ & $80-160$ & $160-320$ & $\geq 320$ \\
$R I$ & $<150$ & $150-300$ & $300-600$ & $\geq 600$ & \\
\hline
\end{tabular}

\subsubsection{Risk Assessment Code}

Assessment of soil heavy metal pollution was mainly based on the total concentration currently, and the speciation of heavy metals was often neglected. In fact, the acid-soluble fraction was the real reason for the risk. Therefore, methods of ecological risk assessment based on acid-soluble heavy metals, such as risk assessment code, have provided a new idea for ecological risk assessment of heavy metal pollution. Perin et al. put forward this method in 1985 [37]. The RAC was used to assess the risk and mobility of non-stable fractions of the metals [8], expressed as the percentage acid-soluble fraction (Table 2). 
Table 2. Classification of risk assessment code (RAC).

\begin{tabular}{cc}
\hline Risk & Acid Soluble Fraction (\%) \\
\hline No risk & $<1$ \\
Low risk & $1-10$ \\
Medium risk & $11-30$ \\
High risk & $31-50$ \\
Very high risk & $51-75$ \\
\hline
\end{tabular}

\subsection{Source Identification and Apportionment}

\subsubsection{Source Identification}

\section{GIS Mapping}

GIS is a spatial information analysis technology that has developed rapidly in recent years. It has a powerful spatial analysis function, and is widely used in source identification. The greatest advantage of this technology is that it can convert huge amounts of data information into a more intuitive spatial distribution map in the process of source identification, and utilize the spatial distribution maps to qualitatively identify the pollution sources. In general, GIS mapping can distinguish point source pollution from non-point source pollution [38]. In spatial analysis using ArcMap 10.0 software, the Kriging method was used for spatial interpolation.

\section{Coefficient of Variation (CV)}

When comparing the degrees of dispersion of two groups of data, it is not appropriate to use the standard deviation (SD) if the dimensions of the two groups are different. The CV overcomes this problem because it involves the ratio of the standard deviation of raw data to the mean value, as follows:

$$
\mathrm{CV}=\frac{\mathrm{SD}}{\text { Mean }}
$$

Coefficient of variation can be divided into three grades: low variation $(\mathrm{CV}<15 \%)$, medium variation $(15 \%<\mathrm{CV}<36 \%)$, and high variation $(\mathrm{CV}>36 \%)$ [39].

Coefficient of variation of heavy metal concentration can reflect the interference degree of human activities to environmental media. Generally speaking, environmental media that is strongly affected by human activities may produce a higher coefficient of variation of heavy metal concentration [39]. There are similarities between source identification by calculating coefficient of variation and by using GIS mapping. A high coefficient of variation and an uneven spatial distribution of heavy metals concentration can indicate a high proportion of human sources.

\section{Correlation Analysis of Heavy Metals}

Correlation analysis is a relatively simple and convenient method for source identification of heavy metal pollution, and it is one of the most widely used methods currently. Through the correlation analysis of heavy metals, some effective information about the pollution sources has been obtained. It can provide some important information for the further analysis of pollution sources, and also can verify the results of source apportionment obtained by other methods. In general, when the concentrations of two heavy metals are significantly positively correlated, the two heavy metals may be homologous, and when they are negatively correlated, they may have different sources [40]. In this study, Pearson correlation analysis was used in SPSS software. Remarkably, most multivariate statistical methods require variables to conform to the normal distribution. Thus, the normality of the distribution of each variable was checked by analyzing kurtosis and skewness statistical tests before Pearson correlation analysis [41,42]. 


\section{Enrichment Factors (EF)}

Enrichment factor (EF) is a useful tool for determining the degree of anthropogenic heavy metal pollution $[11,23]$. It was used to describe metal enrichment in agricultural soil, because it is necessary to reduce the effect of grain size on contamination through the normalization of concentration data with respect to a conservative element $[9,43]$. Iron is inert in migration processes and is derived mainly from natural lithogenic sources, so it is generally recognized as being an appropriate normalization element [44]. The EF values for elements in soil samples were thus calculated as follows [44]:

$$
E F=\frac{\left(C_{i} / C_{F e}\right) \text { sample }}{\left(C_{i} / C_{F e}\right) \text { crust }}
$$

where $C_{i}$ is the element concentration in the sample or continental crust, and $C_{F e}$ is the concentration of the reference element $(\mathrm{Fe})$. Background values for soils in Jiangsu Province were taken as continental crust values: Fe $3.02 \%$, Cd $0.126 \mathrm{mg} \mathrm{kg}^{-1}, \mathrm{Cr} 77.8 \mathrm{mg} \mathrm{kg}^{-1}, \mathrm{Cu} 22.3 \mathrm{mg} \mathrm{kg}^{-1}$, Ni $26.7 \mathrm{mg} \mathrm{kg}^{-1}$, $\mathrm{Pb} 26.2 \mathrm{mg} \mathrm{kg}^{-1}$, and $\mathrm{Zn} 62.6 \mathrm{mg} \mathrm{kg}^{-1}$ [45]. An EF value of $0.5-1.5$ indicates that a metal is derived mainly from crustal materials or natural weathering processes, while EF $>1.5$ indicates that a significant portion originated from non-crustal or anthropogenic processes [46].

\subsubsection{Source Apportionment by Positive Matrix Factorization (PMF)}

The above methods only qualitatively identify the major sources of heavy metals in soil. However, it is impossible to quantitatively calculate the contribution rate of each type of pollution source using them. PMF analysis can achieve the goal of source apportionment.

PMF analysis employed the US EPA PMF 5.0 model for soil pollutant source apportionment, as developed by Paatero and Tapper [47]. The PMF is a typical receptor model and can be used without source composition as an input. The notable features of this approach are non-negativity constraints in obtaining physically realistic meanings, and the use of uncertainty to weight each data point individually [48]. Furthermore, PMF can supplement values that are missing or below detection limits to ensure the reliability of each data point [26].

The PMF model defines an $\mathrm{n} \times \mathrm{m}$ original data matrix $X$, where $\mathrm{n}$ represents the number of samples and $\mathrm{m}$ the number of chemical species, which can be factorized into two sub-matrices, namely $G(\mathrm{n} \times \mathrm{p})$ and $F(\mathrm{p} \times \mathrm{m})$, with an unexplained part $E(\mathrm{n} \times \mathrm{m})[26,49]$, as follows:

$$
\begin{gathered}
X=G+F \\
x_{i j}=\sum_{k=1}^{p} g_{i k} f_{k j}+e_{i j}
\end{gathered}
$$

where $x_{i j}$ is the concentration of the $j$ th chemical species measured in the $i$ th sample; $g_{i k}$ is the contribution of source $k$ to the ith sample; $f_{k j}$ is the concentration of the $j$ th chemical species in source $k$; and $e_{i j}$ is the residual for each sample and species. The residual error matrix, $e_{i j}$, is obtained by minimizing the function $Q$, where

$$
Q=\sum_{i=1}^{n} \sum_{j=1}^{m}\left(\frac{e_{i j}}{u_{i j}}\right)^{2}
$$

and $u_{i j}$ is the uncertainty of the $j$ th chemical species for sample $i$. The model can be optimized by including the uncertainty, $u$, for each sample, calculated using the measurement uncertainty (MU) and detection limit (MDL). When the metal concentration is $\leq \mathrm{MDL}, u$ is calculated as

$$
u=\frac{5}{6} \times \mathrm{MDL}
$$


and when the concentration is $>$ MDL, we have

$$
u=\sqrt{(\mathrm{MU} \times \text { concentration })^{2}+(\mathrm{MDL})^{2}}
$$

\section{Results and Discussion}

\subsection{Concentrations of Heavy Metals in Soils}

\subsubsection{Descriptive Statistics of Soil Properties}

Descriptive statistics of soil properties are shown in Table 3. The $\mathrm{pH}$ of the soil ranged from 4.89 to 7.45 , with an average of 5.81. The proportion of samples in which $\mathrm{pH}$ was less than 7 among the 32 soils was $93.75 \%$. Soil cation exchange capacity (CEC) is an important factor reflecting soil buffer capacity, and also an important basis for evaluating soil nutrient holding capacity, improving soil equality, and rational fertilization. The average soil cation exchange capacity in the study area was $18.41 \mathrm{cmol} \cdot \mathrm{kg}^{-1}$, which belongs to a medium-upper level. Soil electrical conductivity (EC) is an index for determining water-soluble salts in soil, and it is a factor to determine whether salt ions in soil restrict crop growth or not. Different plants have different optimum intervals for soil conductivity. The average conductivity of soil in the study area was $1.59 \mathrm{~ms} / \mathrm{cm}$. Soil organic matter content (OM) is an index reflecting soil fertility. According to soil fertility classification recommended by the second national soil census, if the organic matter of a soil is less than $1 \%$, it is organic matter deficient soil. There was no sample in which the organic matter was less than $1 \%$, which indicated that the soil fertility in the study area was relatively good. Soil particle size was related to soil adsorption capacity of heavy metals. Generally, the smaller the particle size of soil is, the stronger the adsorption capacity and the higher the heavy metal concentration would be. The average soil particle size in the study area was $24.37 \Phi$.

Table 3. Soil properties including $\mathrm{pH}$, cation exchange capacity (CEC), electrical conductivity (EC), organic matter $(\mathrm{OM})$, and particle size.

\begin{tabular}{|c|c|c|c|c|}
\hline Soil Properties & Range & Mean Value & Standard Deviation & CV \\
\hline $\mathrm{pH}$ & $4.85-7.45$ & 5.81 & 0.69 & 0.12 \\
\hline $\mathrm{CEC}\left(\mathrm{cmol} \cdot \mathrm{kg}^{-1}\right)$ & $11.76-22.99$ & 18.41 & 2.60 & 0.14 \\
\hline $\mathrm{EC}\left(\mathrm{ms} \cdot \mathrm{cm}^{-1}\right)$ & $0.67-3.05$ & 1.59 & 0.65 & 0.41 \\
\hline OM (\%) & $1.84-5.35$ & 3.58 & 0.94 & 0.26 \\
\hline Average particle size $(\Phi)$ & $8.45-52.06$ & 24.37 & 8.37 & 0.34 \\
\hline
\end{tabular}

CV: Coefficient of Variation.

\subsubsection{Descriptive Statistics of Total Heavy Metal Concentrations}

Basic statistics related to the total heavy metal concentrations in soils from the Lihe River Watershed and other selected areas are summarized in Table 4, together with background values of soil in Jiangsu Province and standard values (Soil Environmental Quality Standard Two, SEQ-II, GB 15618-1995, grade II for agricultural land). SEQ-II values are threshold values for the protection of human health and agricultural production in China. A wide range of total heavy metal concentrations was observed in soils across the study area (Table 4), and mean $\mathrm{Cd}, \mathrm{Cu}, \mathrm{Pb}$, and $\mathrm{Zn}$ concentrations were all higher than their respective background values (the $\mathrm{Cd}$ concentration was four times the background value). Mean $\mathrm{Cr}$ and $\mathrm{Ni}$ concentrations were lower than their background values. The $\mathrm{Cd}, \mathrm{Cr}, \mathrm{Cu}, \mathrm{Ni}, \mathrm{Pb}$, and $\mathrm{Zn}$ concentrations exceeded background values in $100 \%, 3 \%, 31 \%, 25 \%, 94 \%$, and $94 \%$ of the 32 soil samples, respectively. Comparison of mean metal concentrations with SEQ-II values indicates that $\mathrm{Cd}$ pollution is the most serious, with a concentration almost twice the SEQ-II value, indicating that anthropogenic sources have a direct effect on soil $\mathrm{Cd}$ concentrations [50]. The $\mathrm{CV}$ values of metal concentrations followed the order $\mathrm{Cd}(0.72)>\mathrm{Pb}(0.52)>\mathrm{Cu}(0.42)>\mathrm{Zn}(0.39)>\mathrm{Ni}(0.20)>\mathrm{Cr}(0.17)$. 
Table 4. Total heavy metal concentrations in soil from the Lihe River Watershed and other selected areas for comparison (unit mg $\mathrm{kg}^{-1}$ ).

\begin{tabular}{|c|c|c|c|c|c|c|c|c|c|}
\hline \multirow{2}{*}{ Heavy Metals } & \multicolumn{6}{|c|}{ The Lihe River Watershed } & \multirow{2}{*}{$\begin{array}{l}\text { Background Values of } \\
\text { Soil in Jiangsu Province }\end{array}$} & \multirow{2}{*}{ SEQ-II } & \multirow{2}{*}{$\begin{array}{c}\begin{array}{c}\text { The Yangtze Rive } \\
\text { Estuary, China }\end{array} \\
\text { Mean } \\
\end{array}$} \\
\hline & Range & Mean \pm SD & Median & First Quartile & Third Quartile & $\mathrm{CV}$ & & & \\
\hline $\mathrm{Cd}$ & $0.28-2.62$ & $0.57 \pm 0.41$ & 0.45 & 0.40 & 0.59 & 0.72 & 0.13 & 0.3 & 0.19 \\
\hline $\mathrm{Cr}$ & $39.71-79.66$ & $54.60 \pm 9.04$ & 53.95 & 47.64 & 59.61 & 0.17 & 77.8 & 200 & 79.1 \\
\hline $\mathrm{Cu}$ & $11.68-46.83$ & $22.71 \pm 9.44$ & 21.17 & 16.09 & 22.96 & 0.42 & 22.3 & 100 & 24.7 \\
\hline $\mathrm{Ni}$ & $16.31-34.11$ & $24.35 \pm 4.88$ & 24.05 & 21.10 & 27.17 & 0.20 & 26.7 & 50 & 31.9 \\
\hline $\mathrm{Pb}$ & $21.26-141.72$ & $39.78 \pm 20.61$ & 36.75 & 29.10 & 43.13 & 0.52 & 26.2 & 300 & 23.8 \\
\hline $\mathrm{Zn}$ & $57.14-238.06$ & $93.29 \pm 38.50$ & 82.61 & 76.08 & 93.45 & 0.39 & 62.6 & 250 & 82.9 \\
\hline References & \multicolumn{6}{|c|}{ Present study } & Chen et al. [4] & Chen et al. [4] & Wang et al. [9] \\
\hline
\end{tabular}


In comparisons with other regions (Table 4) the mean concentration of $\mathrm{Cd}$ in the Lihe River Watershed $\left(0.57 \mathrm{mg} \mathrm{kg}^{-1}\right)$ was higher than that in the Yangtze and Pearl river systems $(0.19$ and $0.32 \mathrm{mg} \mathrm{kg}^{-1}$, respectively [9,51], while concentrations of the other metals were both higher and lower. This indicates that the problem of high Cd levels in soil of the Lihe River Watershed requires attention.

Spatial distributions of the metals are shown in Figure 2, revealing that the distributions of $\mathrm{Cd}$, $\mathrm{Pb}, \mathrm{Cu}$, and $\mathrm{Zn}$ are largely similar, being higher in central-eastern and southern parts of the study area. $\mathrm{Cr}$ and $\mathrm{Ni}$ are distributed relatively uniformly over the whole study area, although they occur at slightly higher levels in the west and lower levels in the east.

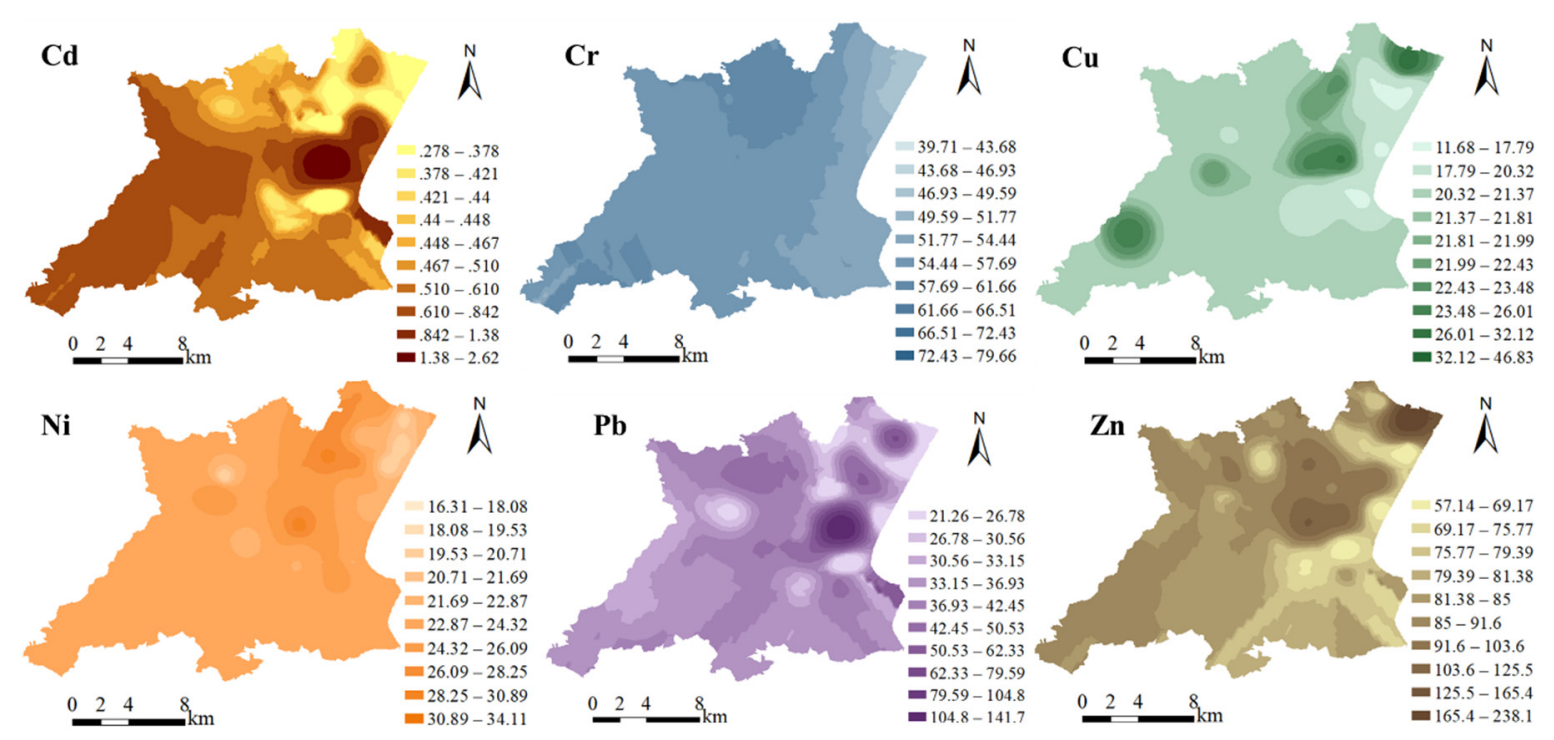

Figure 2. Spatial distributions of $\mathrm{Cd}, \mathrm{Cr}, \mathrm{Cu}, \mathrm{Ni}, \mathrm{Pb}$, and $\mathrm{Zn}$ concentrations $(\mathrm{mg} / \mathrm{kg})$ in the study area.

The spatial distributions of elements were determined with the kriging interpolation method.

\subsubsection{Acid-Soluble Heavy Metal Concentration}

The ratio of acid-soluble concentration to total concentration of six heavy metals can reflect the mobility of heavy metals in soil. Descriptive statistics of acid-soluble heavy metal concentrations are shown in Table 5. The order of acid-soluble concentrations of the six heavy metals was $\mathrm{Pb}>\mathrm{Cu}>\mathrm{Cd}>$ $\mathrm{Zn}>\mathrm{Ni}>\mathrm{Cr}$, which indicated that the mobility of $\mathrm{Pb}$ and $\mathrm{Cu}$ was relatively high, while that of $\mathrm{Ni}$ and $\mathrm{Cr}$ was low. The result was consistent with the study by Dario et al. [51]. This suggested that for $\mathrm{Cr}$ and $\mathrm{Ni}$, the input ratio of anthropogenic sources was relatively low, while it was high for $\mathrm{Pb}$ and $\mathrm{Cu}$. It is noteworthy that the mobile heavy metals in soil are easily absorbed by plants, and eventually enter the human body through the food chain, which poses a great threat to the human body. Therefore, $\mathrm{Pb}$, $\mathrm{Cu}, \mathrm{Cd}$, and $\mathrm{Zn}$ in the soil of the study area are the key heavy metals that posed a threat to the human body and need to be paid attention, while the threat of $\mathrm{Cr}$ and $\mathrm{Ni}$ to the human body is relatively small.

Table 5. The available concentration of six heavy metals in the soil.

\begin{tabular}{cccc}
\hline Heavy Metals & Range & Mean Value \pm Standard Deviation & Coefficient of Variation \\
\hline $\mathrm{Cd}$ & $0.11-1.54$ & $0.25 \pm 0.25$ & 98.16 \\
$\mathrm{Cr}$ & $0.60-1.85$ & $1.27 \pm 0.26$ & 20.01 \\
$\mathrm{Cu}$ & $7.45-34.00$ & $14.85 \pm 7.09$ & 47.76 \\
$\mathrm{Ni}$ & $1.16-4.18$ & $2.64 \pm 0.77$ & 29.29 \\
$\mathrm{~Pb}$ & $12.51-91.84$ & $26.84 \pm 13.61$ & 50.73 \\
$\mathrm{Zn}$ & $9.32-59.10$ & $18.92 \pm 11.44$ & 60.46 \\
\hline
\end{tabular}




\subsubsection{Correlation between Heavy Metal Concentration and Soil Properties}

The correlation between heavy mental concentration and soil properties is shown in Table 6 . It was suggested that the total concentration of $\mathrm{Cr}$ was significantly correlated with $\mathrm{CEC}$ and $\mathrm{pH}$. The available concentrations of $\mathrm{Cr}$ and $\mathrm{Ni}$ were positively correlated with $\mathrm{CEC}$ at 0.01 level. However, for other heavy metals, there was no correlation between the concentration and soil properties. Thus, $\mathrm{Cr}$ and $\mathrm{Ni}$ were more affected by soil properties. Whether this result indicates that $\mathrm{Cr}$ and $\mathrm{Ni}$ derived mainly from parent material is a question worthy of further verification.

Table 6. The correlation between heavy mental concentration and soil properties.

\begin{tabular}{cccccc}
\hline Heavy Metals & $\mathbf{p H}$ & CEC & EC & OM & Average Particle Size \\
\hline $\mathrm{Cd}-\mathrm{s}$ & 0.222 & 0.123 & 0.287 & 0.132 & 0.033 \\
$\mathrm{Cr}-\mathrm{s}$ & $0.444^{*}$ & $0.449^{* *}$ & 0.316 & 0.266 & -0.223 \\
$\mathrm{Cu}-\mathrm{s}$ & 0.229 & 0.075 & 0.146 & 0.076 & 0.103 \\
$\mathrm{Ni}-\mathrm{s}$ & 0.041 & 0.040 & 0.024 & -0.098 & -0.131 \\
$\mathrm{~Pb}-\mathrm{s}$ & 0.098 & 0.115 & 0.255 & 0.182 & -0.038 \\
$\mathrm{Zn}-\mathrm{s}$ & -0.008 & -0.117 & -0.086 & -0.226 & -0.113 \\
$\mathrm{Cd}-\mathrm{sa}$ & 0.199 & 0.081 & 0.216 & 0.122 & 0.072 \\
$\mathrm{Cr}-\mathrm{sa}$ & 0.215 & $0.627^{* *}$ & 0.301 & 0.285 & -0.334 \\
$\mathrm{Cu}-\mathrm{sa}$ & 0.123 & 0.049 & 0.075 & 0.067 & 0.184 \\
$\mathrm{Ni}-\mathrm{sa}$ & -0.120 & $0.457^{* *}$ & 0.130 & 0.032 & -0.154 \\
$\mathrm{~Pb}-\mathrm{sa}$ & 0.044 & 0.124 & 0.247 & 0.194 & -0.062 \\
$\mathrm{Zn}-\mathrm{sa}$ & -0.062 & -0.242 & -0.111 & -0.309 & -0.104 \\
\hline
\end{tabular}

Notes: "Cd-s" denotes the concentration of $\mathrm{Cd}$ in soil; “Cd-sa" denotes the available concentration of $\mathrm{Cd}$ in soil. It was same as "Cr, $\mathrm{Cu}, \mathrm{Ni}, \mathrm{Pb}$, and $\mathrm{Zn}$." In addition, "**" indicates correlation was significant at the 0.01 level (two-tailed), while "** indicates correlation was significant at the 0.05 level (two-tailed). CEC: cation exchange capacity; EC: electrical conductivity; OM: organic matter.

\subsection{Risk Assessment of Heavy Metals in Soil}

\subsubsection{Potential Ecological Risk Indices}

Potential ecological risks of the metals were calculated using Equations (1) and (2), with results presented in Table 7. Mean potential ecological risks are ranked as $\mathrm{Cd}>\mathrm{Pb}>\mathrm{Cu}>\mathrm{Ni}>\mathrm{Zn}>\mathrm{Cr}$. The $E_{i}$ values (Equation (1)) for $\mathrm{Cr}, \mathrm{Cu}, \mathrm{Ni}, \mathrm{Pb}$, and $\mathrm{Zn}$ are all $<40$, indicating low potential ecological risk, whereas $\mathrm{Cd}\left(E_{i}=131.9\right)$ poses a considerable risk. The mean $R I$ value (Equation (2)) for the study area indicates a moderate risk, to which the $E_{i}$ value for Cd contributes $86.8 \%$ of the potential ecological risk.

Table 7. Descriptive statistics of $E_{i}$ and $R I$ for heavy metals in the study area.

\begin{tabular}{cccccccc}
\hline Parameter & $\begin{array}{c}\text { Heavy } \\
\text { Metal }\end{array}$ & Mean & Max & Min & SD & CV & $\begin{array}{c}\text { Risk } \\
\text { Classification }\end{array}$ \\
\hline \multirow{6}{*}{$E_{i}$} & $\mathrm{Cd}$ & 131.9 & 604.4 & 64.16 & 95.26 & 0.722 & Considerable risk \\
& $\mathrm{Cr}$ & 1.403 & 2.048 & 1.021 & 0.232 & 0.166 & Low risk \\
& $\mathrm{Cu}$ & 5.093 & 10.50 & 2.619 & 2.117 & 0.416 & Low risk \\
& $\mathrm{Ni}$ & 4.560 & 6.388 & 3.054 & 0.914 & 0.200 & Low risk \\
& $\mathrm{Pb}$ & 7.592 & 27.04 & 4.057 & 3.933 & 0.518 & Low risk \\
& $\mathrm{Zn}$ & 1.490 & 3.803 & 0.913 & 0.615 & 0.413 & Low risk \\
\hline $\mathrm{RI}$ & (Multi-metal) & 152.0 & 649.5 & $300-600$ & 99.79 & 0.656 & Moderate risk \\
\hline
\end{tabular}

SD: Standard Deviation; CV: Coefficient of Variation.

\subsubsection{Risk Assessment Code}

The acid-soluble fraction indicates the degree of mobility of heavy metals in soil, further reflecting ecological risk, and follows the order $\mathrm{Pb}>\mathrm{Cu}>\mathrm{Cd}>\mathrm{Zn}>\mathrm{Ni}>\mathrm{Cr}$ (Table 8). According to the RAC 
classification (Table 2), $\mathrm{Pb}, \mathrm{Cu}$, and $\mathrm{Cd}$ exhibit the highest mobility and therefore the greatest potential bio-available risk, with 43-68\% solubility. The lower acid solubility of Zn and Ni indicate medium risk, with low risk for $\mathrm{Cr}$. Overall, the environmental risk of the bio-available fraction, based on RAC values, decreases in the order $\mathrm{Pb}>\mathrm{Cu}>\mathrm{Cd}>\mathrm{Zn}>\mathrm{Ni}>\mathrm{Cr}$, indicating that $\mathrm{Pb}, \mathrm{Cu}$, and $\mathrm{Cd}$ pose the greatest ecological risk in the Lihe River Watershed.

Table 8. Acid-soluble fraction of heavy metals in soil and their risk classifications.

\begin{tabular}{ccc}
\hline Heavy Metals & Acid Soluble Fraction (\%) & Risk Classification \\
\hline $\mathrm{Cd}$ & $43.02 \pm 10.35$ & High risk \\
$\mathrm{Cr}$ & $2.36 \pm 0.46$ & Low risk \\
$\mathrm{Cu}$ & $65.19 \pm 10.29$ & Very high risk \\
$\mathrm{Ni}$ & $11.25 \pm 4.05$ & Medium risk \\
$\mathrm{Pb}$ & $67.72 \pm 6.97$ & Very high risk \\
$\mathrm{Zn}$ & $19.79 \pm 4.72$ & Medium risk \\
\hline
\end{tabular}

\subsection{Identification and Apportionment of Pollution Sources}

\subsubsection{Identification of Pollution Sources}

\section{GIS Mapping of Heavy Metals}

GIS mapping can assist in distinguishing point from non-point sources, and in identifying potential pollutant sources $[2,20,21,24]$. The higher $\mathrm{Cd}, \mathrm{Pb}, \mathrm{Cu}$, and $\mathrm{Zn}$ concentrations tend to be clustered in circular patterns around specific points (Figure 2), indicating point-source pollution. In contrast, $\mathrm{Cr}$ and $\mathrm{Ni}$ concentrations are relatively uniform, with no obvious low or high values in the study area, indicating geological background or non-point sources.

\section{Coefficient of Variation of Metal Concentrations}

Generally, the greater the $\mathrm{CV}$, the higher the contribution of anthropogenic sources to metals in soils [40]. Therefore, the calculated CV values (Table 4) indicate that $\mathrm{Cd}, \mathrm{Pb}, \mathrm{Cu}$, and $\mathrm{Zn}(\mathrm{CV}=0.39-0.72)$ are derived mainly from anthropogenic sources, while $\mathrm{Cr}$ and $\mathrm{Ni}(\mathrm{CV}=0.17-0.20)$ are mainly crustal in origin.

\section{Correlations between Metals}

Inter-elemental relationships can provide information regarding pollution sources [52], as the heavy metals of most interest commonly have a shared origin [53]. Before correlation analysis, the normality of the distribution of heavy metal concentration was checked [42]. Through analysis in SPSS, our statistical data were conformed to normal distribution. Pearson correlation coefficients for metal concentrations (Table 9) indicate highly positive correlations $(p \leq 0.01)$ between $\mathrm{Cd}$ and $\mathrm{Pb}(\mathrm{r}=0.84)$, $\mathrm{Cr}$ and $\mathrm{Ni}(\mathrm{r}=0.68), \mathrm{Cu}$ and $\mathrm{Zn}(\mathrm{r}=0.76)$, and $\mathrm{Cu}$ and $\mathrm{Pb}(\mathrm{r}=0.62)$, indicating that these pairs of metals may have the same origin.

Table 9. Pearson correlation coefficients for heavy metals $(n=32)$.

\begin{tabular}{ccccccc}
\hline Heavy Metals & $\mathbf{C d}$ & $\mathbf{C r}$ & $\mathbf{C u}$ & $\mathbf{N i}$ & $\mathbf{P b}$ & $\mathbf{Z n}$ \\
\hline $\mathrm{Cd}$ & 1 & -0.012 & $0.450^{\mathrm{a}}$ & 0.121 & $0.841^{\mathrm{a}}$ & 0.079 \\
$\mathrm{Cr}$ & & 1 & 0.053 & $0.677^{\mathrm{a}}$ & -0.194 & -0.045 \\
$\mathrm{Cu}$ & & 1 & 0.040 & $0.617^{\mathrm{a}}$ & $0.763^{\mathrm{a}}$ \\
$\mathrm{Ni}$ & & & 1 & -0.013 & -0.103 \\
$\mathrm{~Pb}$ & & & 1 & 0.345 \\
$\mathrm{Zn}$ & & & & 1 \\
\hline
\end{tabular}




\section{Enrichment Factors}

The statistics of the EFs for all the metals analyzed were evaluated to further clarify the potential sources of metals in soils in the study area. The EF values for $\mathrm{Cd}$ are highest, with a mean of 15.56, and values for $\mathrm{Pb}$ and $\mathrm{Zn}$ are moderate, with means of 2.63 and 2.58, respectively. Mean EF values (and $\mathrm{CV}$ values) follow the order $\mathrm{Cd}>\mathrm{Pb}>\mathrm{Zn}>\mathrm{Cu}>\mathrm{Ni}>\mathrm{Cr}$. $\mathrm{Cd}, \mathrm{Pb}, \mathrm{Zn}$, and $\mathrm{Cu}$ are thus considered to be enriched $(\mathrm{EF}=1.75-15.56)$, while $\mathrm{Cr}$ and Ni show relatively low enrichment $(\mathrm{EF}=1.19-1.53)$. Considered together, the mean $\mathrm{EF}$ and $\mathrm{CV}$ values (Table 10) indicate that $\mathrm{Cd}, \mathrm{Pb}, \mathrm{Cu}$, and $\mathrm{Zn}$ have anthropogenic origins, whereas $\mathrm{Cr}$ and $\mathrm{Ni}$ are derived from the crust.

Table 10. Descriptive statistics for the enrichment factors (EF) of heavy metals and their coefficient of variation $(\mathrm{CV})$ values.

\begin{tabular}{cccc}
\hline Heavy Metal & Mean \pm SD & Range & CV \\
\hline $\mathrm{Cd}$ & $15.56 \pm 11.68$ & $7.92-74.03$ & 0.75 \\
$\mathrm{Cr}$ & $1.19 \pm 0.12$ & $0.95-1.45$ & 0.10 \\
$\mathrm{Cu}$ & $1.75 \pm 0.80$ & $0.88-3.88$ & 0.45 \\
$\mathrm{Ni}$ & $1.53 \pm 0.18$ & $1.29-2.16$ & 0.12 \\
$\mathrm{~Pb}$ & $2.63 \pm 1.46$ & $1.22-9.63$ & 0.56 \\
$\mathrm{Zn}$ & $2.58 \pm 1.28$ & $1.51-7.84$ & 0.50 \\
\hline
\end{tabular}

\subsubsection{Source Apportionment by PMF}

The PMF model was run using between three and six factors, and each run was initialized with different starting points. A random-seed mode with 20 random starting points was selected and 3-6 factors were examined. PMF analysis identified four appropriate factors among the soils (Table 11). Tentative identification of the factor profiles was based on elemental markers in the different sources.

Table 11. Source contribution for different elements by positive matrix factorization (PMF).

\begin{tabular}{ccccccccc}
\hline \multirow{2}{*}{ Elements } & \multicolumn{2}{c}{ Profile Contribution $\mathbf{( m g} / \mathbf{k g})$} & \multicolumn{4}{c}{ Percentage Contribution (\%) } \\
\cline { 2 - 8 } & Factor 1 & Factor 2 & Factor 3 & Factor 4 & Factor 1 & Factor 2 & Factor 3 & Factor 4 \\
\hline $\mathrm{Ca}$ & 196.84 & $2.9 \times 10^{-15}$ & $5.9 \times 10^{-6}$ & 2220.70 & 8.14 & $1.2 \times 10^{-16}$ & $2.4 \times 10^{-7}$ & 91.86 \\
$\mathrm{Cd}$ & 0.30 & 0.12 & 0.15 & $2.0 \times 10^{-13}$ & 52.11 & 21.62 & 26.27 & $3.5 \times 10^{-11}$ \\
$\mathrm{Co}$ & 0.92 & 4.71 & 7.24 & 8.17 & 4.38 & 22.37 & 34.43 & 38.82 \\
$\mathrm{Cr}$ & 0.21 & 11.23 & 19.52 & 22.82 & 0.40 & 20.88 & 36.30 & 42.43 \\
$\mathrm{Cu}$ & 1.51 & 14.03 & 1.48 & 4.75 & 6.92 & 64.44 & 6.81 & 21.82 \\
$\mathrm{Fe}$ & 254.28 & 3477.7 & 6417.3 & 7712.2 & 1.42 & 19.47 & 35.93 & 43.18 \\
$\mathrm{~K}$ & 69.38 & 2557.1 & 3587.2 & 5308.9 & 0.60 & 22.19 & 31.13 & 46.07 \\
$\mathrm{Mg}$ & $5.3 \times 10^{-5}$ & 491.51 & 982.34 & 1624.2 & $1.7 \times 10^{-6}$ & 15.87 & 31.71 & 52.43 \\
$\mathrm{Mn}$ & 19.46 & 52.68 & 45.14 & 140.26 & 7.55 & 20.46 & 17.53 & 54.46 \\
$\mathrm{Ni}$ & 0.50 & 4.33 & 9.27 & 9.70 & 2.10 & 18.19 & 38.94 & 40.77 \\
$\mathrm{~Pb}$ & 9.74 & 18.90 & 6.01 & 3.53 & 25.51 & 49.50 & 15.74 \\
$\mathrm{Zn}$ & 0 & 56.52 & 6.24 & 28.10 & 0 & 62.21 & 6.87 \\
\hline
\end{tabular}

Source composition profiles based on a four-factor solution are provided in Table 11. Factor 1 is dominated by $\mathrm{Cd}$ and accounts for $52.11 \%$ of the $\mathrm{Cd}$ source. The $\mathrm{EF}$ value for $\mathrm{Cd}$ is the highest of the six metals, averaging 15.56, which indicates Cd is significantly enriched in the soil. In addition, the results of the PERI and RAC assessments indicate that Cd poses a high ecological risk. The widely distributed ceramics industries in the study area use large amounts of Cadmium Yellow pigment, which may be an important source of the $\mathrm{Cd}$ pollution. It is clear, therefore, that the first factor represents a source related to the ceramics industry.

The second factor is dominated by $\mathrm{Cu}, \mathrm{Pb}$, and $\mathrm{Zn}$. Concentrations of these metals are higher than background values, with mean EF values of 1.75, 2.63, and 2.58 (Table 8), respectively, which indicate moderate enrichment in soil. The spatial distributions of $\mathrm{Cu}, \mathrm{Pb}$, and $\mathrm{Zn}$ in the study area are uneven (Figure 2). Previous studies have indicated that industrial and vehicular sources are mainly responsible for $\mathrm{Cu}, \mathrm{Pb}$, and $\mathrm{Zn}$ inputs to soils and the environment [54], with $\mathrm{Cu}$ being mainly from 
machinery manufacturing plants, $\mathrm{Zn}$ (a hardness additive) from tire dust, and $\mathrm{Pb}$ from coal combustion and automobile exhaust emissions [53,55]. Since the phasing out of leaded petrol, the input of $\mathrm{Pb}$ to the environment has reduced, but vehicle brakes and tires still release $\mathrm{Pb}$, meaning that vehicular emissions remain an important source of pollution [54]. The development of coal-fired power stations and heavy vehicle traffic have accompany industrialization in the study area, so the second factor can be attributed to industrial activity and vehicular emissions.

In the third factor, all of the elements have some loading, except for Ca. The large-scale use of agricultural chemicals (e.g., manure, fertilizers, and pesticides) may cause the enrichment of many elements in soil, including $\mathrm{Cd}, \mathrm{Cr}, \mathrm{Cu}, \mathrm{Ni}, \mathrm{Pb}, \mathrm{Zn}, \mathrm{Co}, \mathrm{Mn}, \mathrm{K}$, and $\mathrm{Mg}[26,53,55,56]$. Some of these elements, such as $\mathrm{Cu}, \mathrm{Ni}, \mathrm{Pb}, \mathrm{Zn}, \mathrm{Co}, \mathrm{Mn}, \mathrm{K}$, and $\mathrm{Mg}$, are important nutrients in crop production, and are provided primarily by commercial fertilizers to improve the soil fertility. Some, such as $\mathrm{Cd}, \mathrm{Cr}$, and $\mathrm{Pb}$, are not essential for plant growth and are not intentionally introduced. PMF analysis thus indicates that the third factor represents sources based on agronomic practices.

For the fourth factor, $\mathrm{Ca}, \mathrm{Co}, \mathrm{Cr}, \mathrm{Fe}, \mathrm{K}, \mathrm{Mg}, \mathrm{Mn}$, and Ni received higher weightings than other metals. These elements, in particular $\mathrm{Ca}, \mathrm{K}, \mathrm{Mg}$, and $\mathrm{Mn}$, are associated with crustal material. Minerals in the topsoil of the study area comprise mainly quartz, potassium feldspar, and anorthoclase, which contain $\mathrm{Al} 2 \mathrm{O} 3, \mathrm{CaO}, \mathrm{MgO}, \mathrm{SiO} 2$, and $\mathrm{K} 2 \mathrm{O}$ [26], and these oxides are released during weathering. Concentrations of $\mathrm{Cr}$ and $\mathrm{Ni}$ are slightly lower than background values, and their uniform distribution in the study area and low CVs indicate that they have low spatial variability. The mean EF values of $\mathrm{Cr}$ and $\mathrm{Ni}$ are $\leq 1.5$, indicating minimal enrichment. In addition, PERI and RAC assessments indicate that $\mathrm{Cr}$ and Ni pose low or zero potential ecological risk. This group of elements is thus likely to originate from natural sources, such as mineral weathering and atmospheric precipitation. This is consistent with the findings of previous studies $[7,8,26,53,56]$.

The present results concerning heavy metal source identification are largely consistent with those of previous studies. Xue et al. [26] combined PMF with a geo-statistical approach in Changxing County, Zhejiang Province, and found that $\mathrm{Cd}, \mathrm{Cu}, \mathrm{Pb}$, and $\mathrm{Zn}$ were mainly from anthropogenic sources, while $\mathrm{Cr}$ and Ni were mainly from natural sources. Dai et al. [56] used multivariate analysis and geostatistics to identify the sources of heavy metals in Laiwu City, Shandong Province, Eastern China, and found that $\mathrm{Cd}, \mathrm{Cu}, \mathrm{Pb}$, and $\mathrm{Zn}$, were dominated by industrial, agricultural, and vehicular sources, while $\mathrm{Cr}$ and $\mathrm{Ni}$ came from natural sources and were controlled by parent materials. Peris et al. [57] performed a multivariate statistical analysis of agricultural soils in the European Mediterranean region, and found that $\mathrm{Ni}$ was mainly associated with parental rocks, while $\mathrm{Cd}, \mathrm{Cu}, \mathrm{Pb}$, and $\mathrm{Zn}$ were connected with anthropogenic activity. Using a combination of GIS mapping and multivariate statistical analysis, Cai et al. [53] demonstrated that $\mathrm{Ni}$ and $\mathrm{Cr}$ originate from natural sources, whereas $\mathrm{Cd}$ and $\mathrm{Pb}$ are mainly derived from anthropogenic activity. Li et al. [7] used correlation and multivariate statistical analysis to show that $\mathrm{Cu}, \mathrm{Cd}, \mathrm{Pb}$, and $\mathrm{Zn}$ concentrations in soils were mainly anthropogenic in origin, whereas $\mathrm{Cr}$ and $\mathrm{Ni}$ concentrations were mainly influenced by natural factors, such as parent materials.

Source contribution rates were also determined by PMF (Figure 3). Factor 1 (representing industrial activity related to the ceramics industry) and factor 2 (industrial and vehicular emissions) were combined. The total contributions of industrial and vehicular emissions to $\mathrm{Cu}, \mathrm{Pb}$, and $\mathrm{Zn}$ levels in the agricultural soils are $71.4 \%, 75.0 \%$, and $62.2 \%$, respectively, while agricultural sources contribute $6.8 \%, 15.7 \%$, and $6.9 \%$, respectively, and parent materials contribute $21.8 \%, 9.2 \%$, and $30.9 \%$, respectively. For $\mathrm{Cr}$ and $\mathrm{Ni}$, the contribution rates of parent material are highest, followed by agricultural activity and industrial and vehicular emissions. For $\mathrm{Cd}$, industrial and vehicular emissions, and agricultural sources account for $73.7 \%$ and $26.3 \%$, respectively. There is no natural source of $\mathrm{Cd}$ in the study area, and because $\mathrm{Cd}$ pollution is overwhelmingly identified as the most significant ecological risk factor in the study area, it should have the highest priority in controls imposed on heavy metal pollution by industrial sources. 


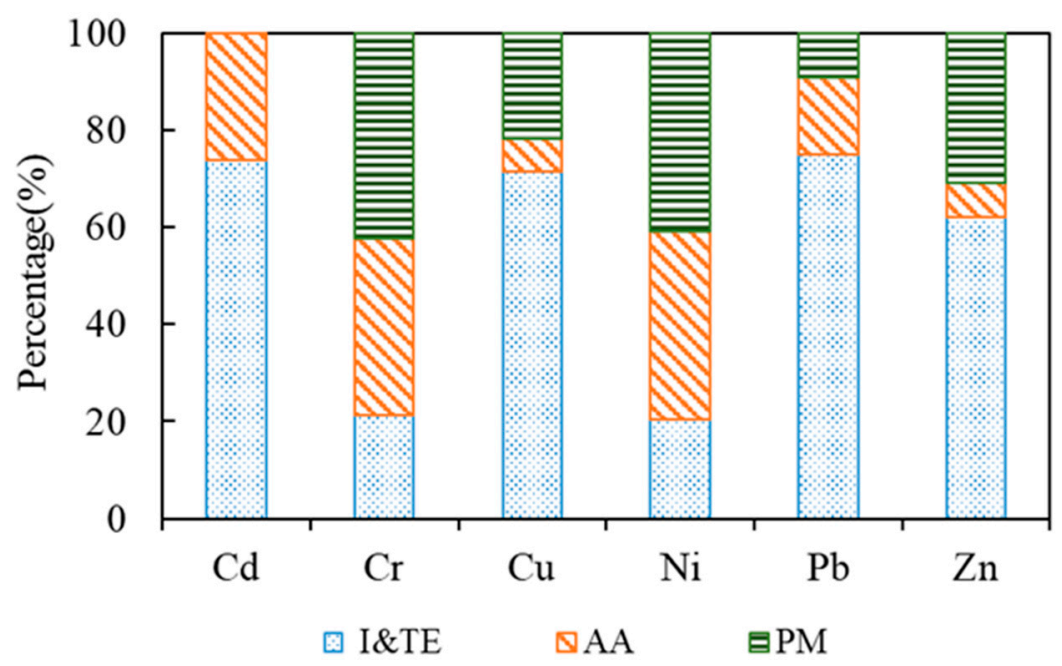

Figure 3. Relative source contributions to the heavy metals analyzed in the present study. I\&TE, AA, and PM represent industrial and vehicular emissions, agricultural activity, and parent materials, respectively.

\section{Conclusions}

This study analyzed the spatial distribution, ecological risks, and sources of the heavy metals $\mathrm{Cd}$, $\mathrm{Cr}, \mathrm{Cu}, \mathrm{Ni}, \mathrm{Pb}$, and $\mathrm{Zn}$ in agricultural soils in the Lihe River Watershed. Average concentrations of $\mathrm{Cd}, \mathrm{Cu}, \mathrm{Pb}$, and $\mathrm{Zn}$ were all higher than background values, with the mean $\mathrm{Cd}$ concentration being four times higher and almost twice the SEQ-II value. Average $\mathrm{Cr}$ and $\mathrm{Ni}$ concentrations were lower than background values. $\mathrm{Cd}, \mathrm{Cu}, \mathrm{Pb}$, and $\mathrm{Zn}$ exhibit similar spatial distributions, with concentrations clearly higher in the central-eastern and southern parts of the study area. In contrast, $\mathrm{Cr}$ and Ni have relatively uniform distributions across whole study area, although slightly higher in the west and slightly lower in the east. Based on the results of PERI and RAC assessments, it was concluded that Cd poses a considerable ecological risk, and it was identified as the most significant factor affecting the ecological environment of the study area.

Source identification based on the combined methods of GIS mapping and CV, correlation, and EF analyses indicates that $\mathrm{Cd}, \mathrm{Pb}, \mathrm{Cu}$, and $\mathrm{Zn}$ are derived mainly from anthropogenic sources, including agricultural, industrial, and vehicular emissions, while $\mathrm{Cr}$ and $\mathrm{Ni}$ originate mainly from natural sources. Source apportionment by PMF analysis indicates that for $\mathrm{Cd}, \mathrm{Cr}, \mathrm{Cu}, \mathrm{Ni}, \mathrm{Pb}$, and $\mathrm{Zn}$ in the agricultural soils, industrial and vehicular emissions contribute $73.7 \%, 21.3 \%, 71.4 \%, 20.3 \%, 75.0 \%$, and $62.2 \%$, respectively; agricultural sources contribute $26.3 \%, 36.3 \%, 6.8 \%, 38.9 \%, 15.7 \%$, and $6.9 \%$, respectively; and parent materials contribute $0 \%, 42.4 \%, 21.8 \%, 40.8 \%, 9.2 \%$, and $30.9 \%$, respectively. Important strategies should be implemented to reduce the use of chemical fertilizers and pesticides and, even more importantly, control industrial point-source pollution to reduce ecological risks associated with Cd pollution.

Supplementary Materials: The following are available online at http://www.mdpi.com/1660-4601/16/12/2094/s1, Table S1: Operating parameters for ICP-MS (ELAN 9000, PerkinElmer SCIEX) for the determination of elemental concentrations, Figure S1: The distribution of heavy metal concentration in the study area.

Author Contributions: S.Z., S.W. and G.W. conceived and designed the experiments and supervised the quality of the article; C.W. and L.C. performed the experiments; Z.X. and Z.C. provided the payment for publishing the article and put forward suggestions for revision of the article analyzed the data; and L.C. wrote the paper.

Funding: This research was funded by the Comprehensive Geological Survey in the Coastal Area of Northeastern Hainan Island (DD20190308), the National Natural Science Foundation of China (41771243), the Comprehensive Geological Survey of Beibu Gulf and Other Key Coastal Zones (DD20160146), the National Key Research and Development Plan (2017YFD0800305), the Special Fund for Research in the Public Interest of the Ministry of Land and Resources (201511001-03) and Guangdong Natural Science Foundation Project (2018A0303130063).

Conflicts of Interest: The authors declare no conflict of interest. 


\section{References}

1. Chen, T.; Liu, X.M.; Li, X.; Zhao, K.; Zhang, J.B.; Xu, J.M.; Shi, J.C.; Dahlgren, R.A. Heavy metal sources identification and sampling uncertainty analysis in a field-scale vegetable soil of Hangzhou, China. Environ. Pollut. 2009, 157, 1003-1010. [CrossRef] [PubMed]

2. Shao, S.; Hu, B.; Fu, Z.; Wang, J.; Lou, G.; Zhou, Y.; Jin, B.; Li, Y.; Shi, Z. Source Identification and Apportionment of Trace Elements in Soils in the Yangtze River Delta, China. Int. J. Environ. Res. Public Health 2018, 15, 1240. [CrossRef] [PubMed]

3. Shamuyarira, K.K.; Gumbo, J.R. Assessment of heavy metals in municipal sewage sludge: A case study of Limpopo province, South Africa. Int. J. Environ. Res. Public Health 2014, 11, 2569-2579. [CrossRef] [PubMed]

4. Chen, L.; Zhou, S.; Shi, Y.; Wang, C.; Li, B.; Li, Y.; Wu, S. Heavy metals in food crops, soil, and water in the Lihe River Watershed of the Taihu Region and their potential health risks when ingested. Sci. Total Environ. 2017, 615, 141. [CrossRef] [PubMed]

5. Laidlaw, M.A.S.; Filippelli, G.M.; Brown, S.; Paz-Ferreiro, J.; Reichman, S.M.; Netherway, P.; Truskewycz, A.; Ball, A.S.; Mielke, H.W. Case studies and evidence-based approaches to addressing urban soil lead contamination. Appl. Geochem. 2017, 83, 14-20. [CrossRef]

6. Lu, A.; Wang, J.; Qin, X.; Wang, K.; Han, P.; Zhang, S. Multivariate and geostatistical analyses of the spatial distribution and origin of heavy metals in the agricultural soils in Shunyi, Beijing, China. Sci. Total Environ. 2012, 425, 66. [CrossRef] [PubMed]

7. Li, C.; Wang, F.; Cao, W.; Pan, J.; Lv, J.; Wu, Q. Source analysis, spatial distribution and pollution assessment of heavy metals in sewage irrigation area farmland soils of Longkou city. Environ. Sci. 2017, 38, 1018-1027.

8. Ke, X.; Gui, S.; Huang, H.; Zhang, H.; Wang, C.; Guo, W. Ecological risk assessment and source identification for heavy metals in surface sediment from the Liaohe River protected area, China. Chemosphere 2017, 175, 473. [CrossRef]

9. Wang, H.; Wang, J.; Liu, R.; Yu, W.; Shen, Z. Spatial variation, environmental risk and biological hazard assessment of heavy metals in surface sediments of the Yangtze River estuary. Mar. Pollut. Bull. 2015, 93, 250-258. [CrossRef]

10. Liu, E.; Wang, X.; Liu, H.; Liang, M.; Zhu, Y.; Li, Z. Chemical speciation, pollution and ecological risk of toxic metals in readily washed off road dust in a megacity (Nanjing) China. Ecotoxicol. Environ. Saf. 2019, 173, 381-392. [CrossRef]

11. Maanan, M.; Saddik, M.; Maanan, M.; Chaibi, M.; Assobhei, O.; Zourarah, B. Environmental and ecological risk assessment of heavy metals in sediments of Nador lagoon, Morocco. Ecol. Indic. 2015, 48, 616-626. [CrossRef]

12. Perin, G.; Fabris, R.; Manente, S.; Wagener, A.R.; Hamacher, C.; Scotto, S. A five-year study on the heavy-metal pollution of Guanabara Bay sediments (Rio de Janeiro, Brazil) and evaluation of the metal bioavailability by means of geochemical speciation. Water Res. 1997, 31, 3017-3028. [CrossRef]

13. Duodu, G.O.; Goonetilleke, A.; Ayoko, G.A. Potential bioavailability assessment, source apportionment and ecological risk of heavy metals in the sediment of Brisbane River estuary, Australia. Mar. Pollut. Bull. 2017, 117, 523-531. [CrossRef] [PubMed]

14. Cao, C.; Zhang, Q.; Ma, Z.B.; Wang, X.M.; Chen, H.; Wang, J.J. Fractionation and mobility risks of heavy metals and metalloids in wastewater-irrigated agricultural soils from greenhouses and fields in Gansu, China. Geoderma 2018, 328, 1-9. [CrossRef]

15. Kachenko, A.G.; Singh, B. Heavy Metals Contamination in Vegetables Grown in Urban and Metal Smelter Contaminated Sites in Australia. Water Air Soil Pollut. 2006, 169, 101-123. [CrossRef]

16. Franco-Uría, A.; López-Mateo, C.; Roca, E.; Fernández-Marcos, M.L. Source identification of heavy metals in pastureland by multivariate analysis in NW Spain. J. Hazard. Mater. 2009, 165, 1008-1015. [CrossRef] [PubMed]

17. Liang, Y.; Jiang, X.; Li, G.; Ren, H.; Yang, F.; Cao, Q. Content analysis and risk evaluation of heavy metal elements in soil and ginseng root from nonforested land base with cultivated ginseng in Jilin Province. J. Plant Res. Environ. 2015, 24, 68-76.

18. Brady, J.P.; Ayoko, G.A.; Martens, W.N.; Goonetilleke, A. Enrichment, distribution and sources of heavy metals in the sediments of Deception Bay, Queensland, Australia. Mar. Pollut. Bull. 2014, 81, $248-255$. [CrossRef] [PubMed] 
19. Chen, J.B.; Gaillardet, J.; Bouchez, J.; Louvat, P.; Wang, Y.N. Anthropophile elements in river sediments: Overview from the Seine River, France. Geochem.Geophys. Geosyst. 2015, 15, 4526-4546. [CrossRef]

20. Li, X.; Lee, S.L.; Wong, S.C.; Shi, W.; Thornton, I. The study of metal contamination in urban soils of Hong Kong using a GIS-based approach. Environ. Pollut. 2004, 129, 113. [CrossRef]

21. Zhang, X.Y.; Lin, F.F.; Wong, M.T.F.; Feng, X.L.; Wang, K. Identification of soil heavy metal sources from anthropogenic activities and pollution assessment of Fuyang County, China. Environ. Monit. Assess. 2009, 154, 439. [CrossRef] [PubMed]

22. Maas, S.; Scheifler, R.; Benslama, M.; Crini, N.; Lucot, E.; Brahmia, Z.; Benyacoub, S.; Giraudoux, P. Spatial distribution of heavy metal concentrations in urban, suburban and agricultural soils in a Mediterranean city of Algeria. Environ. Pollut. 2010, 158, 2294-2301. [CrossRef] [PubMed]

23. Tume, P.; Roca, N.; Rubio, R.; King, R.; Bech, J. An assessment of the potentially hazardous element contamination in urban soils of Arica, Chile. J. Geochem. Explor. 2018, 184, 345-357. [CrossRef]

24. Xie, Y.; Chen, T.B.; Lei, M.; Yang, J.; Guo, Q.J.; Song, B.; Zhou, X.Y. Spatial distribution of soil heavy metal pollution estimated by different interpolation methods: Accuracy and uncertainty analysis. Chemosphere 2011, 82, 468. [CrossRef] [PubMed]

25. Tóth, G.; Hermann, T.; Szatmári, G.; Pásztor, L. Maps of heavy metals in the soils of the European Union and proposed priority areas for detailed assessment. Sci. Total Environ. 2016, 565, 1054-1062. [CrossRef] [PubMed]

26. Xue, J.L.; Zhi, Y.Y.; Yang, L.P.; Shi, J.C.; Zeng, L.Z.; Wu, L.S. Positive matrix factorization as source apportionment of soil lead and cadmium around a battery plant (Changxing County, China). Environ. Sci. Pollut. Res. 2014, 21, 7698-7707. [CrossRef] [PubMed]

27. Li, H.P.; Huang, W.Y.; Yang, G.S.; Liu, X.M. Non-point pollutant concentrations for different land uses in Lihe River watershed of Taihu Region China. Environ. Sci. 2006, 26, 243-247.

28. Li, Q.; Chen, Y.; Fu, H.; Cui, Z.; Shi, L.; Wang, L.; Liu, Z. Health risk of heavy metals in food crops grown on reclaimed tidal flat soil in the Pearl River Estuary, China. J. Hazard. Mater. 2012, 227, 148-154. [CrossRef]

29. Gao, W.; Du, Y.; Wang, D.; Gao, S. Distribution Patterns of Heavy Metal in Sediment and Their Influence on the Environment Quality of the Intertidal Flat of Luoyuan, Bay, Fujian Coast. Environ. Sci. 2012, 33, 3097-3103.

30. Cheng, P.; Gao, S.; Bokuniewicz, H. Net sediment transport patterns over the Bohai Strait based on grain size trend analysis. Estuar. Coast. Shelf Sci. 2004, 60, 203-212. [CrossRef]

31. Huang, M.; Zhou, S.; Sun, B.; Zhao, Q. Heavy metals in wheat grain: Assessment of potential health risk for inhabitants in Kunshan, China. Sci. Total Environ. 2008, 405, 54-61. [CrossRef] [PubMed]

32. Kwak, J.I.; Nam, S.-H.; Kim, S.W.; Bajagain, R.; Jeong, S.-W.; An, Y.-J. Changes in soil properties after remediation influence the performance and survival of soil algae and earthworm. Ecotoxicol. Environ. Saf. 2019, 174, 189-196. [CrossRef] [PubMed]

33. Xie, X.; Pu, L.; Shen, H.; Wang, X.; Zhu, M.; Ge, Y.; Sun, L. Effects of soil reclamation on the oat cultivation in the newly reclaimed coastal land, eastern China. Ecol. Eng. 2019, 129, 115-122. [CrossRef]

34. Hu, X.; Zhang, Y.; Luo, J.; Wang, T.; Lian, H.; Ding, Z. Bioaccessibility and health risk of arsenic, mercury and other metals in urban street dusts from a mega-city, Nanjing, China. Environ. Pollut. 2011, 159, 1215-1221. [CrossRef] [PubMed]

35. Lu, S.G.; Bai, S.Q. Contamination and potential mobility assessment of heavy metals in urban soils of Hangzhou, China: Relationship with different land uses. Environ. Earth Sci. 2010, 60, 1481-1490. [CrossRef]

36. Saravanan, P.; Krishnakumar, S.; Pradhap, D.; Silva, J.D.; Arumugam, K.; Magesh, N.S.; Srinivasalu, S. Elemental concentration based potential ecological risk (PER) status of the surface sediments, Pulicat lagoon, Southeast coast of India. Mar. Pollut. Bull. 2018, 133, 107-116. [CrossRef] [PubMed]

37. Gan, G.; Liu, W.; Qiu, Y.; Li, K.; Hou, H.; Peng, P.; Liao, B. Heavy metal pollution and ecological risk assessment of the paddy soils in a smelting area in Central Hunan. Environ. Chem. 2013, 32, 132-137.

38. Huang, Y.; Li, T.; Wu, C.; He, Z.; Japenga, J.; Deng, M.; Yang, X. An integrated approach to assess heavy metal source apportionment in peri-urban agricultural soils. J. Hazard. Mater. 2015, 299, 540-549. [CrossRef]

39. Lv, J.; Liu, Y.; Zhang, Z.; Dai, J. Factorial kriging and stepwise regression approach to identify environmental factors influencing spatial multi-scale variability of heavy metals in soils. J. Hazard. Mater. 2013, 261, 387-397. [CrossRef] 
40. Wang, S.; Cai, L.; Wen, H.; Luo, J.; Wang, Q.; Liu, X. Spatial distribution and source apportionment of heavy metals in soil from a typical county-level city of Guangdong Province, China. Sci. Total Environ. 2019, 655, 92-101. [CrossRef]

41. Naifar, I.; Pereira, F.; Zmemla, R.; Bouaziz, M.; Elleuch, B.; Garcia, D. Spatial distribution and contamination assessment of heavy metals in marine sediments of the southern coast of Sfax, Gabes Gulf, Tunisia. Mar. Pollut. Bull. 2018, 131, 53-62. [CrossRef] [PubMed]

42. Reimann, C.; Filzmoser, P.; Fabian, K.; Hron, K.; Birke, M.; Demetriades, A.; Dinelli, E.; Ladenberger, A. The concept of compositional data analysis in practice:Total major element concentrations in agricultural and grazing land soils of Europe. Sci. Total Environ. 2012, 426, 196-210. [CrossRef] [PubMed]

43. Huang, P.; Li, T.G.; Li, A.C.; Yu, X.K.; Hu, N.J. Distribution, enrichment and sources of heavy metals in surface sediments of the North Yellow Sea. Cont. Shelf Res. 2014, 73, 1-13. [CrossRef]

44. Hu, X. Size Distribution and Source Apportionment of Airborne Metallic Elements in Nanjing, China. Aerosol Air Qual. Res. 2013, 13, 1796-1806. [CrossRef]

45. Hu, W.; Wang, H.; Dong, L.; Huang, B.; Borggaard, O.K.; Bruun Hansen, H.C.; He, Y.; Holm, P.E. Source identification of heavy metals in peri-urban agricultural soils of southeast China: An integrated approach. Environ. Pollut. 2018, 237, 650-661. [CrossRef] [PubMed]

46. Zhang, J.; Liu, C.L. Riverine Composition and Estuarine Geochemistry of Particulate Metals in ChinaWeathering Features, Anthropogenic Impact and Chemical Fluxes. Estuar. Coast. Shelf Sci. 2002, 54, 1051-1070. [CrossRef]

47. Paatero, P.; Tapper, U. Positive matrix factorization: A non-negative factor model with optimal utilization of error estimates of data values. Environmetrics 1994, 5, 111-126. [CrossRef]

48. Paatero, P. Least squares formulation of robust non-negative factor analysis. Chemom. Intell. Lab. Syst. 1997, 37, 23-35. [CrossRef]

49. Wang, C.; Wu, S.; Zhou, S.L.; Wang, H.; Li, B.; Chen, H.; Yu, Y.; Shi, Y. Polycyclic aromatic hydrocarbons in soils from urban to rural areas in Nanjing: Concentration, source, spatial distribution, and potential human health risk. Sci. Total Environ. 2015, 375, 527-528. [CrossRef]

50. Chai, M.; Shi, F.; Li, R.; Shen, X. Heavy metal contamination and ecological risk in Spartina alterniflora marsh in intertidal sediments of Bohai Bay, China. Mar. Pollut. Bull. 2014, 84, 115. [CrossRef]

51. Di Giuseppe, D.; Vittori Antisari, L.; Ferronato, C.; Bianchini, G. New insights on mobility and bioavailability of heavy metals in soils of the Padanian alluvial plain (Ferrara Province, northern Italy). Geochemistry 2014, 74, 615-623. [CrossRef]

52. Tang, W.; Shan, B.; Zhang, H.; Mao, Z. Heavy metal sources and associated risk in response to agricultural intensification in the estuarine sediments of Chaohu Lake Valley, East China. J. Hazard. Mater. 2010, 176, 945. [CrossRef] [PubMed]

53. Cai, L.; Xu, Z.; Ren, M.; Guo, Q.; Hu, X.; Hu, G.; Wan, H.; Peng, P. Source identification of eight hazardous heavy metals in agricultural soils of Huizhou, Guangdong Province, China. Ecotoxicol. Environ. Saf. 2012, 78, 2-8. [CrossRef] [PubMed]

54. Imperato, M.; Adamo, P.; Naimo, D.; Arienzo, M.; Stanzione, D.; Violante, P. Spatial distribution of heavy metals in urban soils of Naples city (Italy). Environ. Pollut. 2003, 124, 247-256. [CrossRef]

55. Duzgoren-Aydin, N.S.; Weiss, A.L. Use and abuse of Pb-isotope fingerprinting technique and GIS mapping data to assess lead in environmental studies. Environ. Geochem. Health 2008, 30, 577-588. [CrossRef] [PubMed]

56. Dai, B.; Shu, L.J.; Cheng, Z.J.; Lu, Z.Z.; Yang, L.; Jia, Z.R. Assessment of Sources, Spatial Distribution and Ecological Risk of Heavy Metals in Soils in a Typical Industry-based City of Shandong Province, Eastern China. Environ. Sci. 2015, 36, 507.

57. Peris, M.; Recatalá, L.; Micó, C.; Sánchez, R.; Sánchez, J. Increasing the Knowledge of Heavy Metal Contents and Sources in Agricultural Soils of the European Mediterranean Region. Water Air Soil Pollut. 2008, 192, 25-37. [CrossRef]

(C) 2019 by the authors. Licensee MDPI, Basel, Switzerland. This article is an open access article distributed under the terms and conditions of the Creative Commons Attribution (CC BY) license (http://creativecommons.org/licenses/by/4.0/). 